\title{
Major Salivary Gland Neoplasm
}

National Cancer Institute

\section{Source}

National Cancer Institute. Major Salivary Gland Neoplasm. NCI Thesaurus. Code C4407.

A benign or malignant neoplasm that affects the major salivary glands. Representative examples of benign neoplasms include Warthin tumor, monomorphic adenoma, and pleomorphic adenoma. Representative examples of malignant neoplasms include carcinoma, lymphoma, and sarcoma. 